\title{
Aspectos éticos da coautoria em publicações científicas
}

\author{
Carla Mara Hilário \\ Mestra; Universidade Estadual Paulista, Marília, SP, Brasil; \\ hilariopesquisa@gmail.com \\ Maria Cláudia Cabrini Grácio \\ Doutora; Universidade Estadual Paulista, Marília, SP, Brasil; \\ cabrini@marilia.unesp.br \\ José Augusto Chaves Guimarães \\ Doutor; Universidade Estadual Paulista, Marília, SP, Brasil; \\ guima@marilia.unesp.br
}

\begin{abstract}
Resumo: A coautoria científica pressupõe a participação intelectual ativa de todos os autores na elaboração de uma pesquisa. Todavia, existem entendimentos variados sobre a concepção das atividades de colaboração científica e coautoria, que, por vezes, confundem pesquisadores no processo de atribuição de autoria em pesquisas colaborativas. A vista disso, esta pesquisa objetiva refletir sobre os aspectos éticos da atribuição da autoria em publicações científicas, a partir da reflexão e debate sobre a participação e colaboração entre autores no desenvolvimento de uma pesquisa científica e a consequente responsabilidade sobre os resultados gerados e comunicados à comunidade científica. Para tanto, são analisados os conceitos e as funções de um autor, no intuito de evidenciar a distinção entre colaboração científica e coautoria e, mais especificamente, os aspectos éticos envolvidos na atribuição de autoria na ciência. Observa que, embora existam normas de conduta ética na ciência, deve haver, por parte dos pesquisadores, uma reflexão acerca dos problemas de atribuição de autoria, uma vez que os aspectos éticos da produção científica são indissociáveis dos aspectos sociais e das políticas e práxis da área. Isso leva a concluir que tratar dos aspectos éticos da coautoria durante a formação do pesquisador pode ser uma estratégia para minimizar problemas associados a essa questão, além de incentivar estudos que viabilizem uma discussão mais verticalizada sobre o tema, tornando-o parte do processo de construção do conhecimento.
\end{abstract}

Palavras-chave: Ética na coautoria. Ética na colaboração. Ética em publicações científicas. Coautoria. Colaboração científica.

\section{Introdução}

A colaboração científica é uma estratégia de trabalho adotada por pesquisadores para viabilizar, facilitar e potencializar a realização de pesquisas científicas, 
principalmente aquelas de natureza empírica e/ou experimental. Essa atividade, que envolve a participação de indivíduos trabalhando com um objetivo em comum, se compõe da soma de habilidades e conhecimentos, oferecendo a possibilidade de realizar estudos mais aprofundados, com diferentes perspectivas e abordagens e com análises mais precisas e elaboradas, além de possibilitar maior agilidade e redução de tempo na construção do trabalho.

Ao se falar em ética na atribuição de autoria, é preciso considerar a complexidade subjacente a este processo, principalmente em caso de pesquisas colaborativas, que pode envolver diferentes níveis de contribuições e participações na pesquisa, indo desde aspectos mais substanciais para a construção de um trabalho científico, como a sua idealização (em termos de delimitação do problema de pesquisa, especificação dos objetivos, elaboração da revisão teórica, delineamento metodológico e estabelecimento dos critérios de análise dos resultados), até contribuições ou colaborações, muitas vezes de caráter técnico e pontual.

As coautorias caracterizam-se como um produto da colaboração substancial entre pesquisadores, pressupondo interações em atividades científicas por meio de uma ação coletiva. Essa atividade interativa consolida, ao longo do tempo, uma relação de mútua confiança entre os pesquisadores, de tal modo que as relações de colaboração constituem uma forma de capital social acadêmico-científico. Em outras palavras, quando os pesquisadores colaboram em projetos em que partilham quantidades substanciais de conhecimento, é formado um estoque de conhecimento que beneficia mutuamente os pesquisadores envolvidos (ABBASI; WIGAND; HOSSAIN, 2014).

A prática da colaboração científica e, por decorrência, da coautoria envolve também aspectos éticos e morais que vão além da dimensão do conteúdo do texto para atingir substancialmente a indicação de autoria. Com a crescente prática da coautoria em pesquisas e a prevalência da autoria múltipla em diversas áreas do conhecimento, a preocupação com as questões éticas na coautoria em publicações científicas tem levado instituições de pesquisa, conselhos de classe e até mesmo pesquisadores interessados no assunto, a construírem diretrizes e normas sobre o comportamento ético no processo de 
atribuição de autoria, na tentativa de minimizar os efeitos negativos da "hiperautoria" na Ciência.

A principal crítica à hiperautoria em produções científicas consiste no questionamento sobre a necessidade de se atribuir a autoria de uma pesquisa a muitos pesquisadores, colocando em dúvida a credibilidade do estudo e a participação de todos os autores em seu desenvolvimento. Em outras palavras, a constatação da hiperautoria leva ao questionamento daquilo que, a rigor, possa ser considerada como autoria e, no caso concreto, em que medida toda aquela profusão de autores ali nominados efetivamente contribuiu intelectualmente para a construção do texto. Em suma, busca-se combater a questão da "autoria promíscua" ocorrida ao atribuir autoria a alguém que não contribuiu de forma intelectualmente significativa para a elaboração do estudo (STANGE, 2008).

A ética pode ser entendida em seu sentido amplo como "[...] a ciência da conduta humana perante o ser e seus semelhantes [...]” (SÁ, 2000, p. 15), reafirmando os dois elementos que lhe são intrínsecos: o homem e a sociedade em uma concepção ampla de bem agir ou bem fazer, o que revela o modo pelo qual uma dada sociedade, a partir de seus próprios valores, espera que ocorram o comportamento individual e as relações interpessoais (WECKER; ADENEY, 2000). Integrando o espectro de estudo da Filosofia, a ética centra-se nos valores e nas regras de conduta do homem em sociedade a partir de conceitos como bem, ação correta, dever, obrigação, virtude, liberdade, racionalidade e escolha (BLACKBURN, 1997). Seu objeto específico reside nos objetos morais em todas as suas formas de evoluir, a partir do comportamento moral, dos valores morais e das moralidades, delimitadas no tempo e no espaço (SÁNCHEZ VÁZQUEZ, 1975; SEVERINO, 1994; SROUR, 1998), razão pela qual Cortina e Martinez (2005) a ela se referem como Filosofia Moral, que contempla a reflexão sobre as questões morais, explicando o fenômeno moral e remetendo à concepção da ética racional, decorrente das ideias de Kant, que parte da existência de uma consciência moral espontânea para estabelecer princípios de bem agir e de bem fazer (MARCONDES, 2001).

O livre arbítrio constitui requisito fundamental a toda ação que possa ser eticamente aceitável ou não, pois sem a liberdade de escolha não se pode falar 
em responsabilidade pelos atos cometidos (BLACKBURN, 1997; MARTINS, 1994). No âmbito da Ciência da Informação, Fernandez Molina e Guimarães (2002) ressaltam uma tônica preponderante no que se refere às boas práticas e à confiabilidade no exercício profissional, assim como em questões mais específicas relativas, por exemplo, a direitos autorais, liberdade intelectual e censura. A isso se alia a preocupação com os aspectos éticos envolvidos na produção científica (PRADO, 1996; PESSANHA, 1998; NEWMAN; JONES, 2006; LIMA et al., 2012; MANDAL; PARIJA, 2013) e, mais especificamente, na autoria (KROKOSCZ, 2015).

A preocupação com as questões éticas na atribuição da autoria e coautoria tem se destacado em publicações científicas, principalmente das áreas médicas, onde comumente os artigos são assinados por múltiplos autores. Os estudos que tratam desta questão na atividade científica são realizados, em sua maioria, por pesquisadores da área da saúde, área bastante permeada pelas preocupações éticas, principalmente por lidar com seres humanos. Estes aspectos podem ser observados a partir das Diretrizes e Normas de Pesquisa envolvendo seres humanos, por meio da Resolução 196/96 do Conselho Nacional de Saúde, que tem como objetivo de garantir o amplo direito a todas as pessoas envolvidas na pesquisa: sujeitos de pesquisa, pesquisador, equipe de pesquisa e sociedade como um todo (MUCCIOLI et al., 2006).

A autoria de uma pesquisa é matéria que se situa na intersecção da ciência, da ética e da legislação, afetando pesquisadores, editores, consumidores da informação e cientometristas (WITTER, 2010). Mas, como definir um autor de um trabalho científico? Existem limites explícitos que estabeleçam as diferenças na contribuição de um colaborador e de um coautor? Pensando nestas questões, este artigo apresenta uma reflexão sobre os aspectos éticos da atribuição da autoria em publicações científicas, a partir da análise e debate sobre a noção de autoria e coautoria na ciência. De forma específica, objetiva-se analisar os conceitos e funções de um autor, evidenciar as características que distinguem as atividades de colaboração científica e de coautoria e apresentar os aspectos éticos da autoria na ciência. Este artigo propõe discussões acerca de diretrizes que pautem o processo de atribuição de autoria na publicação das 
pesquisas científicas colaborativas, especialmente considerando que, na ciência contemporânea, muitas pesquisas, em especial aquelas de natureza empírica, demandam, em geral, esforços de mais de um pesquisador para sua elaboração e desenvolvimento. Para tanto, são analisados e descritos os conceitos e as funções de um autor na ciência, a partir da literatura científica nacional e internacional, no intuito de evidenciar a distinção entre colaboração científica e coautoria e, mais especificamente, os aspectos éticos envolvidos na atribuição de autoria na ciência.

\section{Colaboração científica e coautoria: aspectos conceituais e relações}

Os estudos relativos à colaboração científica entre pesquisadores se acentuaram a partir da década de 1960, ainda que esforços colaborativos na ciência, mesmo que em menor quantidade, já ocorriam no século XVII. De acordo com Beaver e Rosen (1978), o primeiro registro de artigo escrito em coautoria entre pesquisadores ocorreu em 1665, envolvendo pesquisadores de diferentes países, na tentativa de realizar um empreendimento cooperativo com metas comuns, esforços coordenados e resultados compartilhados. No século XIX, o crescimento da colaboração científica confirmou a dependência do trabalho em equipe, na crescente profissionalização da ciência. Desse modo, a colaboração se configurou e se configura como uma resposta à profissionalização da ciência (BEAVER; ROSEN, 1978).

Nesse contexto, especialmente nos dias de hoje, entende-se que a interdisciplinaridade da ciência e as constantes avaliações das agências financiadoras de pesquisa impulsionam a interação entre pesquisadores de diferentes áreas, aproximados por temas de interesse, possibilitando a contribuição intelectual específica e aprofundada de cada pesquisador envolvido, o que possibilita obter resultados mais amplos, densos e precisos. Considerando que em pesquisas científicas colaborativas os próprios colaboradores e coautores agem como revisores científicos, seja da elaboração, desenvolvimento e/ou redação científica da pesquisa, tende-se a obter resultados, discussões e conclusões mais lapidadas e amadurecidas. 
A colaboração científica, de modo geral, consiste em atividades de orientação e sugestões para o aperfeiçoamento de um trabalho. Neste contexto, considera-se que a colaboração científica pode ser caracterizada em dois níveis: técnica e científica (ou intelectual). A colaboração técnica pode envolver o compartilhamento de recursos materiais, econômicos, prestação de serviços e apoio técnico (principalmente os remunerados), que pode ser identificada, geralmente, nos agradecimentos do trabalho. Abrange, dessa forma, esforços que contribuem para a realização da pesquisa, porém, sem interferência direta de ideias.

A colaboração científica envolve o compartilhamento de recursos intelectuais e se apresenta como uma atividade mais complexa que a primeira, sendo subdividida em duas categorias: colaboração no conteúdo científico e colaboração na prática científica (Quadro 1).

Quadro 1 - Características da coautoria e da colaboração na pesquisa científica

\begin{tabular}{|c|c|c|}
\hline Coautoria & & Colaboração Científica \\
\hline \multirow{2}{*}{$\begin{array}{l}\text { a) Coparticipação na } \\
\text { redação total ou } \\
\text { parcial dos resultados } \\
\text { das pesquisas; } \\
\text { b) coleta e } \\
\text { organização } \\
\text { dados; } \\
\text { c) análise } \\
\text { resultados; } \\
\text { d) responsabilidade } \\
\text { pelo conteúdo; } \\
\text { e) revisão, orientação } \\
\text { e validação do } \\
\text { conteúdo; }\end{array}$} & $\begin{array}{l}\text { Colaboração no } \\
\text { conteúdo } \\
\text { científico }\end{array}$ & $\begin{array}{l}\text { a) Indicação de leituras; } \\
\text { b) esclarecimento de dúvidas e discussões } \\
\text { sobre o tema; } \\
\text { c) validação do conteúdo, garantida pela } \\
\text { expertise na temática. }\end{array}$ \\
\hline & $\begin{array}{l}\text { Colaboração na } \\
\text { prática científica }\end{array}$ & $\begin{array}{l}\text { a) Orientações sobre a estrutura do } \\
\text { trabalho; } \\
\text { b) orientações sobre técnicas e métodos de } \\
\text { análise; } \\
\text { c) contribuições para construção do } \\
\text { trabalho; } \\
\text { d) orientações sobre a abordagem da obra. }\end{array}$ \\
\hline
\end{tabular}

Fonte: Elaborado pelos autores.

A coautoria, por sua vez, é o resultado da efetiva e substancial colaboração entre os parceiros de uma pesquisa, mais vital e mais ativa do que a simples troca de materiais, informação e comentários (VANZ; STUMPF, 2010). São coautores aqueles que participam intensamente da elaboração da pesquisa e 
assumem a responsabilidade do seu conteúdo, por meio da assinatura conjunta do trabalho, de modo que possam, em qualquer instância, apresentar e defender a ideia original da obra.

Smith (1958) foi um dos primeiros estudiosos a medir o aumento das pesquisas em colaboração científica na literatura, usando como unidade de medida as coautorias. Atualmente, na ciência indexada nas bases de dados internacionais, especialmente em estudos bibliométricos, a colaboração científica é medida pela análise de coautorias, em função da dificuldade de se obter uma metodologia que identifique objetivamente as colaborações entre pesquisadores em domínios grandes. Considera-se que a análise das colaborações por outra metodologia, por exemplo, qualitativa - entrevistas ou questionários-, em lugar das coautorias, pode levar a uma visualização distinta do comportamento científico colaborativo, evidenciando colégios científicos, afinidades temáticas e pessoais, assim como colaborações informais nos diferentes domínios, que não tenham sido evidenciados nas redes de coautoria.

Todavia, a favor da análise de coautoria, destaca-se que, além de ser a forma objetiva de se visualizar o trabalho coletivo entre pesquisadores, a partir da formalização e registro do resultado da investigação, ela evidencia a assinatura conjunta de um trabalho, identificando a responsabilidade ética e moral do conhecimento gerado.

A distinção entre colaboração científica e coautoria é, ainda, um dos aspectos "inexplorados" e imprecisos na literatura da temática, em função das definições mal delimitadas de colaboração e de coautoria, que podem variar consideravelmente entre áreas, instituições e países, ou ainda, ao longo do tempo (SUBRAMANYAM, 1983).

Katz e Martin (1997) ressaltam o fato de que na ciência pode haver circunstâncias em que a atividade colaborativa e a coautoria compreendem eventos distintos. Os autores exemplificam com duas situações:

a) situação A - dois ou mais pesquisadores trabalham em colaboração, mas decidem publicar separadamente. Os motivos podem ser vários, entre eles: decisão de criar uma publicação que sirva como material didático; 
discordância sobre a interpretação dos resultados; prioridades distintas em relação ao canal de comunicação científica; partilha do objeto de pesquisa, dos recursos materiais, técnicos e profissionais, mas objetivos específicos distintos. Neste caso, houve colaboração científica, mas não houve coautoria nas publicações;

b) Situação B - dois ou mais pesquisadores trabalham em suas pesquisas individualmente e decidem reunir os seus resultados e escrevê-los em conjunto, com a interpretação da junção dos dados (no caso de uma pesquisa empírica) e dos resultados sob uma nova perspectiva ou teoria já existente, ou um novo olhar para determinados fenômenos. Neste caso, há coautoria, sem ter ocorrido colaboração científica durante o desenvolvimento das respectivas pesquisas.

Neste contexto, Katz e Martin (1997) relatam que uma análise bibliométrica que avalie a colaboração científica por meio das coautorias, declaradas em um determinado corpus de análise, identifica a situação B como evidência de colaboração científica, em que ocorreu a colaboração na junção e na análise conjunta dos resultados, após o desenvolvimento independente das partes individuais da pesquisa. Todavia, não identifica a atividade colaborativa ocorrida na situação A, que não resultou em assinatura conjunta.

Desse modo, os conceitos de colaboração científica e de coautoria ainda são foco de debates entre pesquisadores da Ciência da Informação. Destaca-se que, embora sejam vistos, usualmente, como uma única atividade, seus conceitos se diferem quando analisados de forma mais profunda, por caracterizarem circunstâncias distintas de interação entre pesquisadores.

Além disso, observa-se, ainda, que não existe um consenso entre os acadêmicos quanto ao conceito de colaboração científica, visto que a ideia relativa a esta prática pode variar muito de acordo com as áreas do conhecimento, e também com a visão particular que cada pesquisador tem sobre tal atividade (VANZ; STUMPF, 2010). Neste contexto, destaca-se que, embora exista um significativo grau de padronização nos artigos científicos contemporâneos, a forma dos artigos reflete diferentes normas metodológicas e 
epistemológicas, explícitas ou implícitas das tradições da área dos seus autores (bem como as influências tecnológicas, econômicas, entre outras) (HJØRLAND, 2002).

Desse modo, a atribuição da autoria deve ocorrer de acordo com a legislação, a epistemologia e as regras da área ou disciplina. A reflexão sobre o significado destes termos é de grande importância para caracterizar o comportamento de domínios científicos, uma vez que a visão individual ou coletiva pode influenciar na forma de agir dos pesquisadores, e consequentemente, as ações podem ser refletidas nos indicadores de ciência.

Nesse contexto, embora existam os manuais de conduta ética na maioria das áreas do conhecimento científico, eles têm um caráter altamente técnico e normativo, não apresentando reflexões relativas às suas sugestões, na medida em que não discutem a forma de publicação como uma questão epistemológica, a qual reflete a generalização e interpretação da experiência científica acumulada de uma área ou disciplina (HJØRLAND, 2002).

Apesar das questões associadas ao uso dos conceitos de coautoria e colaboração científica de forma equivalente, Glänzel (2003) considera que estas são relevantes quando se analisa a colaboração dentro de departamentos, instituições ou em grupos de pesquisa. Todavia, em estudos de colaboração em níveis meso e macro, como aqueles entre instituições ou países, tais questões não procedem e a colaboração pode ser reconhecida por meio da análise de coautoria, dado que nestes níveis, estas tendem a ser revertidas em coautorias.

\section{A ética na atribuição de autoria}

A ética na ciência garante o bem fazer, a conduta aceitável e recomendável que um cientista deve ter em uma comunidade. Na coautoria, espera-se que o pesquisador tenha uma conduta ética no processo de construção do conhecimento e da atribuição de autoria, sendo leal aos fatos, justo com os direitos e obrigações, e responsável em sua função de autor.

Ainda que os elementos éticos sejam tratados na ciência a partir das dimensões teóricas (valores, leis e consciência) e práticas (problemas éticos na 
sociedade), a complexidade das relações humanas pode abranger várias dimensões simultaneamente, dado que não é possível distinguir os aspectos éticos em situações que envolvem também aspectos da práxis da área, além dos políticos, econômicos e psicológicos, entre outros (VALLS, 1994).

Na prática científica, essa combinação de dimensões se torna evidente principalmente nos problemas de atribuição de autoria, que envolvem, além dos problemas de conduta ética, elementos decorrentes das políticas científicas (necessidade de publicar mais, validação da pesquisa, prestígio de pesquisadores mais estabelecidos na ciência) e o desconhecimento da função de autor em uma publicação científica.

Em situações de conflitos, os indivíduos podem se deparar com a necessidade de pautar o seu comportamento por normas que julgam mais apropriadas ou mais dignas de serem cumpridas. Estas normas são aceitas intimamente e reconhecidas como obrigatórias e, de acordo com elas, os indivíduos compreendem que têm o dever de agir de uma determinada maneira pré-acordada pela comunidade. Portanto, pode-se admitir que um indivíduo tende a agir moralmente e que este seu comportamento é o resultado de uma decisão refletida e não puramente espontânea ou natural (VASQUEZ, 1995).

$\mathrm{Na}$ atividade científica, é recomendado que os pesquisadores sigam os manuais de boas práticas científicas, na elaboração da pesquisa e no processo de atribuição de autoria. No entanto, é comum os pesquisadores passarem por situações em que agir de acordo com as regras estabelecidas pela comunidade acadêmica pode acarretar em um conflito de valores. A solução dos problemas éticos e morais não concernem somente a quem a propõe, mas a todas as pessoas que sofrem as consequências da decisão e da ação deste indivíduo (VALLS, 1994).

Pensando nisso, apresenta-se, na Figura 1, a relação entre a autoria, a ética e as normas de conduta na produção científica. Destaca-se que o bem fazer na atividade científica vai muito além do que é considerado aceitável pela comunidade científica, envolvendo também outros elementos, relacionados aos aspectos sociais, psicológicos e políticos. 
A colaboração científica e coautoria são atividades complexas, pois não são somente atividades sociais, mas um empreendimento coletivo que visa somar conhecimentos, habilidades e recursos, com o intuito de produzir conhecimento de melhor qualidade, publicar em periódicos de grande prestígio e potencializar a produção científica. Ambas as atividades estão relacionadas a políticas científicas, da mesma forma que se relacionam com os aspectos psicológicos, ao considerar o desejo de trabalhar próximo a alguém que se gosta, a validação por um pesquisador maduro, parceria entre amigos, afinidades, entre outros.

Figura 1 - Inter-relação entre coautoria e colaboração, ética e produção científica

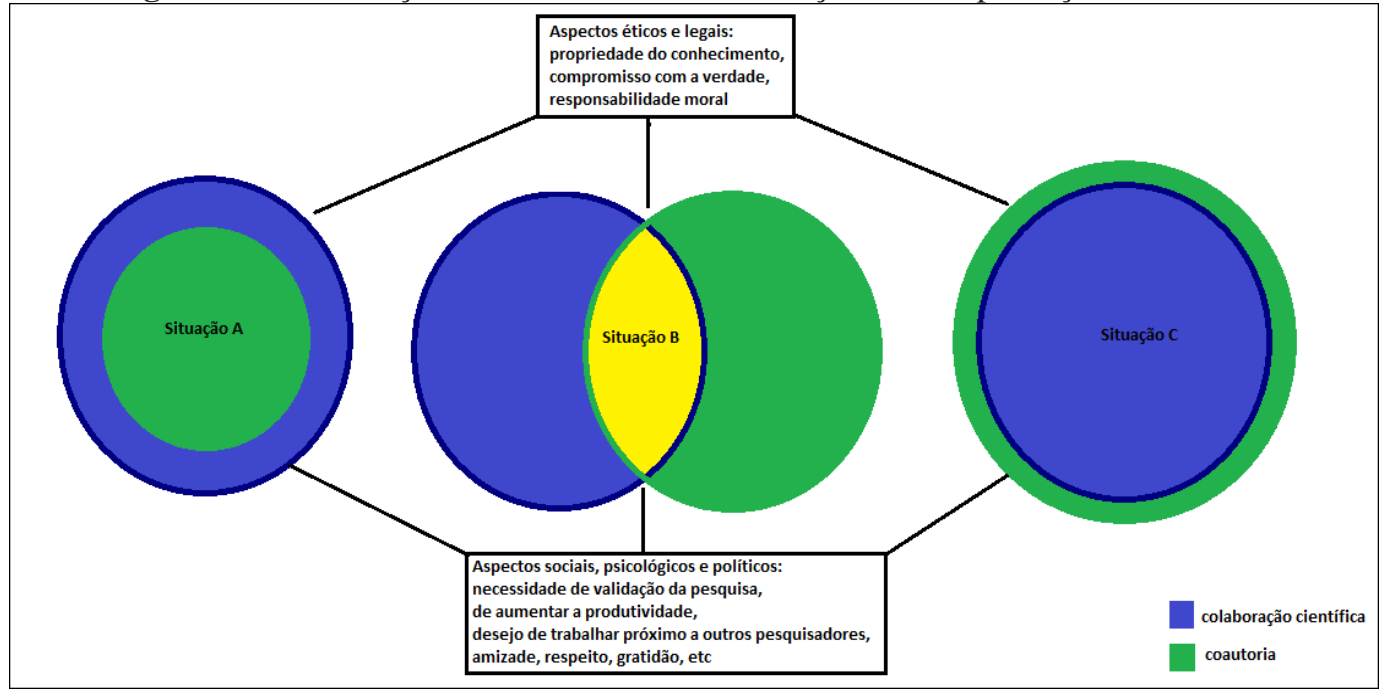

Fonte: Elaborado pelos autores.

Com base na Figura 1, destaca-se que os elementos sociais estão direcionados à prática da colaboração e da coautoria na ciência, e podem revelar as motivações pessoais mesmo com propósitos científicos, como validação da pesquisa e aumentar a produtividade. Todavia, a escolha dos parceiros frequentemente está relacionada aos aspectos psicológicos, como a necessidade de trabalhar próximo a outros pesquisadores, colaborar por amizade e gratidão, principalmente nos casos de colaborações endógenas.

Ainda que a escolha dos coautores seja motivada por uma necessidade da própria pesquisa, como a validação ou contribuição de um conhecimento complementar, a decisão de estabelecer uma relação contínua de colaboração 
sempre está, simultaneamente, associada aos elementos éticos e legais e com os aspectos sociais, ou seja, se na colaboração com determinados autores, há um compromisso com a verdade e uma fiel participação dos envolvidos. Se esta atividade, resultante ou não em coautoria, foi satisfatória para ambos autores, evidenciam-se as relações de amizade, respeito e gratidão, que podem ter surgido antes ou depois da experiência colaborativa. As más experiências com colaborações abusivas ou infiéis raramente levam os autores a consolidarem seus laços.

A ética não prevê solução para todos os problemas prático-morais que os pesquisadores encontram em suas práticas científicas, mas oferece orientações de uma conduta geral para que tenham elementos para refletir acerca da melhor forma de resolver um problema sem prejuízo às pessoas envolvidas, sustentados nas normas que regulam suas áreas.

Ao mesmo tempo em que tomam decisões a fim de resolver os problemas que ocorrem em suas práticas científicas, os pesquisadores avaliam e julgam estas decisões e também ponderam sobre as questões práticas envolvidas, tomando-as como objeto das suas apreciações e reflexões. Neste contexto, ocorre a transição do plano da prática moral para o da teoria moral, ou moral refletida, com o pesquisador como um agente atuante na prática moral, mas que, simultaneamente é modificado por ela, não de modo mecânico, mas reflexivo, remetendo sua teoria à prática. Esta passagem que coincide com os inícios do pensamento filosófico, caracteriza-se pela esfera dos problemas teórico-morais ou éticos (VASQUEZ, 1995) e situa-se na concepção da teoria e prática como filosofia da práxis (KONDER, 1992).

\section{Elementos éticos nas atividades de colaboração científica e coautoria}

O conceito de autor como o indivíduo responsável pela criação de uma obra surge na idade média, como resultado da censura a livros considerados heréticos, com o fim de identificar e condenar os responsáveis pela transgressão. Neste contexto, os autores dos textos com discursos contraventores passam a ser passíveis de punição (CAVALHEIRO, 2008). A questão da atribuição da responsabilidade do conteúdo de uma obra também é presente no âmbito mais 
restrito da ciência, em que ser um autor é assumir a responsabilidade pelo conteúdo de uma obra por ser o agente primário da criação, o condutor do estudo, o analista e o revisor crítico do trabalho.

Montenegro e Alves (1997) consideram que, ao assinar um artigo, o autor estabelece um elo com o trabalho, de modo que a responsabilidade, inclusive ética e moral, é transferida ao autor, o que significa certificar sua integridade e estar apto a defender o trabalho publicamente.

Para publicar uma obra em um veículo de comunicação científica, o pesquisador deve ter ciência da concepção de autor presente nas diretrizes do veículo escolhido e nos códigos de ética da área ou disciplina. Neste sentido, a ideia do que é um autor pode variar entre áreas, sem prescindir, entretanto, da responsabilidade legal e dos direitos atrelados à autoria.

De acordo com o Manual da American Psychological Association (2010), a autoria é reservada para pessoas que fazem uma contribuição substancial e aceitam a responsabilidade por um trabalho publicado. Assim, os pesquisadores devem ter o crédito da autoria em pesquisas que realmente tiveram participação ativa em sua elaboração. De acordo com o Committee on Publication Ethics (COPE), a autoria deve ser atribuída a partir de uma decisão conjunta, de modo que todos os envolvidos tenham ciência e concordância sobre as responsabilidades que implicam a autoria de uma obra (ALBERT; WAGER, 2003).

O manual da APA também orienta que os autores não são apenas aqueles que fazem a escrita real, mas também aqueles que fizeram contribuições científicas substanciais para o estudo. Estas contribuições profissionais substanciais podem incluir: a formulação do problema ou hipótese; estruturação do delineamento experimental; organização e condução do trabalho. Na análise estatística, são autores aqueles que contribuem com a interpretação dos resultados, ou aqueles que escreveram uma grande parte do artigo (AMERICAN PSYCHOLOGICAL ASSOCIATION, 2010).

Segundo o Comitê de Conduta Científica e Ética (CSCE) do National Institutes of Health (NIH), a autoria se refere à lista de nomes dos pesquisadores de um estudo e esta deve basear-se em uma contribuição significativa para a 
conceituação, delineamento, execução ou interpretação da pesquisa, assim como para a elaboração ou revisão ou crítica substancial do artigo oriundo desta pesquisa. Segundo ainda este Comitê, os indivíduos que não atendem a estes critérios, mas que ajudaram na pesquisa, seja por seus encorajamentos e orientação ou por proporcionar espaço, apoio financeiro, reagentes, análises ocasionais ou material para pacientes, devem ser reconhecidos no texto na seção de agradecimentos.

O International Committee of Medical Journals Editors (ICMJE) tem tratado dos critérios de atribuição de autoria, desde suas primeiras reuniões, ainda como Grupo Vancouver. O ICMJE recomenda que a autoria deva ser atribuída com base em três condições:

a) contribuição substancial na concepção e planejamento ou na aquisição de dados ou na análise e interpretação de dados;

b) redação e elaboração do artigo ou revisão intelectual crítica deste;

c) aprovação da versão final a ser publicada.

É recomendado, ainda, que em estudos multicêntricos com grande número de participantes, que o grupo identifique os indivíduos que aceitam a responsabilidade direta pelo manuscrito (MONTEIRO et al., 2004).

Entre as práticas que não devem ser consideradas como coautoria pelo ICMJE, destaca-se: a obtenção de financiamento; coleta de dados ou supervisão geral de um grupo de pesquisa; pessoas não qualificadas para as atividades desenvolvidas na pesquisa; e a pouca participação no desenvolvimento do estudo, além de pouco conhecimento sobre o conteúdo e sobre a participação dos outros autores.

Neste contexto, os autores de um trabalho científico devem mencionar a contribuição dos envolvidos, ou seja, os colaboradores que participaram da realização do estudo. Para isto, as funções de coautor e colaborador devem ser claras, para que não haja atribuições de autoria questionáveis, nem a ausência de atores importantes no desenvolvimento da pesquisa.

Ao considerar a distinção entre as práticas de colaboração científica e coautoria, deve-se estar atento à compreensão sobre essas atividades em 
diferentes áreas do conhecimento, que muitas vezes são fundidas em uma única prática, conforme identifica Hilário e Grácio (2017), ao analisar a equivalência destes termos nas áreas de Matemática, Odontologia e Ciência da Informação. Pensando nisso, tem-se a seguinte questão: Quanto um indivíduo deve contribuir para que sua participação configure coautoria no trabalho a ser publicado?

Com base no Guia de Conduta Científica e Ética, o NHI elaborou um quadro (Figura 2) com orientações para auxiliar na atribuição da autoria (NATIONAL INSTITUTES OF HEALTH, 2016), em que algumas atividades são atribuições inerentes à função de autor, como o trabalho experimental original e elaboração do manuscrito. Por outro lado, o treinamento e formação do pesquisador, como papel de um supervisor, assim como a leitura e/ou comentários sobre o manuscrito, não configuram atividades passíveis de atribuição da autoria intelectual da pesquisa.

Figura 2 - Tipos de contribuição para uma pesquisa, passíveis de atribuição de autoria

\begin{tabular}{|c|c|c|c|}
\hline \multicolumn{4}{|c|}{ Diretrizes gerais para atribuição de autoria } \\
\hline ATIVIDADES & I Requisitos e etapas da pesquisa científica & 1 & Concessão e direito à coautoria \\
\hline $\begin{array}{l}\text { Delineamento da } \\
\text { pesquisa e } \\
\text { interpretação dos } \\
\text { resultados }\end{array}$ & $\left.\right|^{\text {Ideia original, planejamento e coleta }} \begin{array}{l}\text { Outras contribuições intelectuais }\end{array}$ & & $\begin{array}{l}\text { Uma idéia por si só pode não justificar a autoria, a menos } \\
\text { que seja altamente original e única } \\
\text { Sim, mas assumindo envolvimento ativo }\end{array}$ \\
\hline $\begin{array}{l}\text { Papel de } \\
\text { supervisão }\end{array}$ & $\mid \begin{array}{l}\text { Supervisão do projeto } \\
\text { Treinamento, educação } \\
\text { Orientação para o 1ㅇautor }\end{array}$ & & $\begin{array}{l}\text { Sim, mas assumindo envolvimento ativo } \\
\text { Não, a menos que o pesquisador tenha contribuído } \\
\text { substancialmente na elaboração do estudo }\end{array}$ \\
\hline $\begin{array}{l}\text { Apoio técnico e } \\
\text { administrativo }\end{array}$ & $\begin{array}{l}\text { Recursos: Financiamento } \\
\text { Recursos: animais, reagentes } \\
\text { Recursos: pacientes }\end{array}$ & & $\begin{array}{l}\text { Agradecimentos sim, autoria não } \\
\text { Não, se já foi publicado; Sim, se for um produto novo } \\
\text { Talvez, dependendo das circunstâncias }\end{array}$ \\
\hline $\begin{array}{l}\text { Aquisição de } \\
\text { dados }\end{array}$ & $\mid \begin{array}{l}\text { Trabalho experimental original } \\
\text { Trabalho experimental técnico } \\
\text { Análise de dados (ensaios) } \\
\text { Análise de dados (estatísticas) }\end{array}$ & & $\begin{array}{l}\text { Não, se for um trabalho de rotina; Sim, se novos métodos } \\
\text { forem adicionados, ou funções especificas, ex.: } \\
\text { estatísticas, imagens, etc. } \\
\text { Sim, a menos que seja (m) muito básica (s). } \\
\text { Sim, a menos que seja (m) muito básica (s). }\end{array}$ \\
\hline $\begin{array}{l}\text { Redação e } \\
\text { outros }\end{array}$ & $\mid \begin{array}{l}\text { Redação de manuscrito } \\
\text { Leitura / comentários sobre o } \\
\text { manuscrito } \\
\text { Sem participação na redação }\end{array}$ & & $\begin{array}{l}\text { Garante a primeira autoria } \\
\text { Podem ser reconhecido nos agradecimentos } \\
\text { Inclui autoria honorária para chefes de laboratório, grandes } \\
\text { especialistas, etc. }\end{array}$ \\
\hline
\end{tabular}

Fonte: Adaptado de National Institutes of Health (2016).

Nota: Na atividade de delineamento da pesquisa estão incluídas as opções metodológicas e de referência teórica.

Nesse contexto, é importante discutir e estabelecer a questão da autoria e da coautoria com os participantes da pesquisa já na elaboração do projeto. 
Certamente, contar com um quadro previamente aceito pelo grupo facilita muito o trabalho de indicação de quem é ou não autor e sua posição. Esta estratégia pode resolver facilmente a atribuição de autoria para pesquisas que demandam grande quantidade de recursos humanos (WITTER, 2010).

Assim, no início de um estudo envolvendo múltiplos autores, recomenda-se que a divisão das funções de cada coautor seja proporcional à sua participação como autor na obra, de modo que as tarefas realizadas pelos membros sejam substanciais a ponto de configurar a coautoria. Desse modo, é apropriado e recomendável a inclusão de uma seção de agradecimentos para indicar aqueles que colaboraram cientificamente na elaboração do estudo, todavia, não partilham do mérito e responsabilidade da obra. Nesta seção, devem ser incluídos, também, os colaboradores técnicos e financiadores com a justificação de sua contribuição no trabalho (MONTEIRO et al., 2004).

$\mathrm{Na}$ tentativa de apoiar o processo de atribuição de autoria e a ordem dos autores em artigos resultantes de pesquisas colaborativas, Petroianu (2002) propõe 20 critérios no sentido de quantificar, de maneira objetiva, o mérito dos colaboradores que trabalham na pesquisa. $\mathrm{Na}$ proposta do autor, a ordem dos autores e a atribuição da autoria é definida pelo número de pontos (do maior para o menor), em que para ser um autor deve-se atingir 7 pontos. As atividades vão de 6 a 10 pontos e, mesmo que o autor tenha sido o principal idealizador do trabalho, é necessário que participe em mais atividades para que seja configurada sua participação como autor.

Entre os principais critérios e de maior valor listados por Petroianu (2002), estão: criação da ideia; estruturação da metodologia; redação do texto do relato de pesquisa; revisão de literatura; e sugestões importantes incorporadas ao trabalho. Como atividades técnicas que acumulam menor quantidade de pontos estão: criação de instrumentos ou equipamentos para o trabalho; coleta de dados; análises estatísticas; preparação e apresentação do trabalho em eventos científicos; chefia do local de realização da pesquisa, entre outros.

Em casos de pesquisas colaborativas que demandem de opiniões externas para confirmar ideias ou avaliar problemas, pode acontecer de a colaboração ter sido pouco participativa. Uma indicação de literatura, uma orientação temática, 
por exemplo, não garantem que o indivíduo tenha responsabilidade moral sobre a obra em questão. Desse modo, nesta situação, caso o colaborador assine conjuntamente, não possui conhecimento amplo sobre a obra ou teve uma participação ativa em sua elaboração. Neste caso, é inapropriada a atribuição de autoria a este colaborador. Todavia, a decisão de incluí-lo ou excluí-lo pode causar mal estar entre os colaboradores e implicar em problemas de relacionamento e convívio social, tornando mais fácil a decisão de não questionar a participação.

Por outro lado, a "coautoria convidada" definida como a inclusão de pessoas como autores em trabalhos nos quais não participam, pode ocorrer com o objetivo de agradar pessoas hierarquicamente superiores, assim como de aumentar as chances de publicação em função da presença de nomes de maior prestígio e reconhecimento científico na autoria do trabalho (MONTEIRO et al., 2004). Este tipo de coautoria tende a favorecer tanto o pesquisador menos estabelecido, pela visibilidade e prestígio do pesquisador com maior capital científico e social, como o pesquisador de maior maturação acadêmica que se mantem produtivo sem grandes esforços. Vale ressaltar que, dificilmente, esta prática tem consequências e por isto ocorre com muita frequência no ambiente acadêmico.

A coautoria "pressionada", também observada no ambiente acadêmico, principalmente em pesquisas laboratoriais, ocorre quando o responsável do grupo exige a inclusão do seu nome em todos os trabalhos realizados por membros da sua equipe. Frequentemente esta ação é considerada uma "tradição departamental", já enraizada e transmitida entre as gerações de novos pesquisadores sem que, necessariamente, a pressão seja explicitada (MONTEIRO et al., 2004). Nestes casos, há uma inversão de valores, de modo que é considerada ética a inclusão do pesquisador responsável pelo grupo e não inclui-lo seria um problema grave.

Tem-se, ainda, a coautoria fantasma, caracterizada pela omissão de colaboradores que participaram de etapas importantes da pesquisa. Monteiro e coautores (2004) afirmam que frequentemente são os alunos e outros profissionais que não são incluídos como autores, embora tenham contribuído 
significativamente na elaboração do estudo. As razões para esta prática são diversas e vão, desde a preferência por se associar a pesquisadores de maior prestígio, para a maior visibilidade do trabalho, incorrendo na coautoria convidada, até a omissão e falta de reconhecimento de profissionais pouco inseridos no ambiente científico.

Neste contexto, ressalta-se que nem sempre a conduta antiética vem por parte do indivíduo considerado autor, podendo ocorrer a objeção do colaborador a constar como autor, por questões de associação temática ou pelo reconhecimento da pouca contribuição na obra. Além disso, a renúncia do colaborador a figurar como autor pode ser decorrente do pouco conhecimento sobre o assunto geral ou pela competência somente em uma seção específica da obra, podendo sua contribuição ser construída por outro pesquisador. Por este motivo, é importante que os indivíduos que constem como coautores estejam formalmente cientes deste fato e tenham aceitado sua inclusão na lista de autores, uma vez que a assinatura conjunta indica corresponsabilidade sobre o trabalho.

Uma forma de colaboração científica bastante comum é aquela que ocorre entre orientadores e orientandos, visto que durante a elaboração de uma tese é necessária a supervisão ativa de um pesquisador experiente. Para Witter (2010), existem várias situações nas relações orientador-orientando que podem envolver problemas éticos em relação à autoria, sendo as principais situações: quando o orientador copia parte ou todo o trabalho do orientando sem lhe dar o devido crédito; quando o orientador não atribui a autoria ao aluno ou vice-versa, sendo um trabalho realizado em conjunto, ou parte da tese orientada; quando o orientador ou o aluno insere outro(s) autor(es) que não tenha(m) participado significativamente do trabalho, sem discutir a decisão; e quando o orientador submete uma publicação como primeiro autor, sendo o trabalho resultante da tese do aluno.

Nesse contexto, observa-se ainda que, em pesquisas colaborativas envolvendo pesquisadores de diferentes níveis, como aquelas que envolvem doutorandos, mestrandos e seus respectivos orientadores, pode ocorrer o abuso de poder sobre os pesquisadores menos estabelecidos. Henry (2013) se refere a 
este abuso como textploitation, definida como a exploração de textos escritos de forma colaborativa em benefício de um parceiro e em repressão do colaborador parceiro.

No caso de um manuscrito baseado em uma tese ou dissertação de aluno, a expectativa dos editores e pareceristas é que o orientador tenha se envolvido fortemente na elaboração do trabalho. A ética exige que os orientadores que são coautores tenham revisado o trabalho, pois estão mais familiarizados com a estrutura da produção científica na área. Destaca-se, ainda, que um pesquisador com maior maturidade acadêmica, mesmo que não seja orientador, deve assumir a responsabilidade de guiar o pesquisador iniciante durante a realização do estudo e na revisão do trabalho final (BECKER, 2012).

Becker (2012) destaca que a submissão de um manuscrito mal redigido por um pesquisador principiante em coautoria com outro mais estabelecido cientificamente, causa inquietação em uma equipe editorial e, independente da ordem dos autores, fica evidenciado que não houve a participação efetiva do pesquisador mais maduro. A participação ativa dos orientadores e pesquisadores mais estabelecidos é fundamental para estruturar o trabalho de acordo com a cultura da comunidade científica, a partir do seu lastro científico. Ao acompanhar o desenvolvimento da pesquisa e revisar o manuscrito, evitam a confusão de conceitos, a junção de perspectivas divergentes ao relacionar autores com visões opostas e validam a pesquisa.

\section{Considerações finais}

A falta de conhecimento sobre a distinção das atividades de colaboração e coautoria, somada a cultura de determinadas áreas do conhecimento tendem a influenciar no processo de indicação da autoria e coautoria, atribuindo responsabilidade legal a colaboradores que tiveram participações pouco significativas nas pesquisas, podendo levar a uma conduta antiética na atribuição do mérito e responsabilidade do conhecimento científico construído.

A conduta antiética na atribuição da coautoria, embora possa parecer inofensiva, tem significativas consequências na comunidade científica, uma vez que pode prejudicar os demais pesquisadores em disputas por promoções 
acadêmicas e por concessão de financiamentos pelas agências e instituições que fomentam o desenvolvimento da área ou disciplina. Além disso, como apontam Monteiro e outros (2004), fere um dos princípios básicos da ciência - a transparência- e coloca em suspeição a credibilidade da pesquisa e do sistema de reconhecimento, atribuição de mérito e estrutura da ciência.

Considera-se que é difícil avaliar se a conduta antiética na coautoria é resultante da falta de regulamentação em revistas e meios de comunicação científicos, conforme constatado na literatura que fundamentou este estudo, ou trata-se da cultura competitiva resultante da Política do Publish or Perish, que exige a super produtividade dos cientistas.

Essa política de produtividade e competitividade no ambiente acadêmico tem levado, muitas vezes, à "salamização" ou fatiamento da ciência, decorrente da fragmentação da publicação dos "produtos" das pesquisas, desconsiderando o tempo necessário para o amadurecimento das reflexões e discussões relativas aos resultados obtidos, que poderia levar à publicação de artigos com contribuições mais significativas para o progresso do campo científico, em razão da necessidade ou ambição de aumentar a produtividade de um pesquisador, instituição ou país (LEMOS, 2005; CASTIEL; SANZ-VALERO, 2007).

Nesse contexto, considera-se que as diretrizes para os autores e códigos de ética que orientam e reforçam a ideia da boa prática da produção e comunicação científica são de suma importância para garantir a credibilidade da coautoria e reduzir a incidência da conduta antiética de autores. Embora este assunto não tenha sido amplamente considerado em diversos periódicos brasileiro, conforme destacado nos estudos de Silva, Hilário e Martinez-Ávila (2017), e de acordo com guia de boas práticas científicas do COPE, os editores devem fornecer orientação sobre os critérios de autoria e sobre quem deve aparecer como coautor seguindo as regras do campo pertinente (ALBERT; WAGER, 2003).

Conclui-se que tratar os aspectos éticos da coautoria durante a formação do pesquisador pode ser uma estratégia para minimizar os problemas na atribuição da autoria. Estudos que foquem a ética na coautoria também é uma forma de expor publicamente o problema, proporcionando debates e discussões 
sobre o assunto e tornando o tema parte do processo de construção do conhecimento.

Recomenda-se, por fim, que sejam desenvolvidos manuais com orientações relativas à conduta ética na pesquisa tratando especificamente da área de Ciências Sociais Aplicadas, como é o caso da Ciência da Informação, oriundas de reflexões sobre a epistemologia da área, considerando que publicações desta natureza são encontradas em abundância nas áreas da saúde, mas pouco tem sido mencionado sobre o assunto nas demais áreas do conhecimento. Acredita-se que o debate relativo aos aspectos éticos associados à autoria e coautoria das publicações científicas pode estimular periódicos e códigos de ética a incluir, em seus critérios de aceitação de trabalhos e conduta de profissionais, normas que vêm sendo propostas em nível internacional, a fim de dar credibilidade à produção científica sem perder os benefícios e vantagens das práticas colaborativas na construção do conhecimento.

\section{Financiamento}

Esta pesquisa é financiada pela Coordenação de Aperfeiçoamento de Pessoal de Nível Superior (CAPES).

\section{Referências}

ALBERT, T.; WAGER, E. How to handle authorship disputes: a guide for new researchers. [S.1.]: COPE, 2003. Disponível em: <http://publicationethics.o rg/resources>. Acesso em: 10 jun. 2017.

ABBASI, A.; WIGAND, R. T.; HOSSAIN, L. Measuring social capital through network analysis and its influence on individual performance. Library $\&$ Information Science Research, London, v. 36, n. 1, p. 66-73, Jan. 2014.

\section{AMERICAN PSYCHOLOGICAL ASSOCIATION. Publication Manual of} the American Psycological Association. 6. ed. Washington: APA, 2010.

CASTIEL, L. D.; SANZ-VALERO, J. Entre fetichismo e sobrevivência: o artigo científico é uma mercadoria acadêmica? Cadernos de Saúde Pública, Rio de Janeiro, v. 23, n. 12, p. 3041-3050, dez. 2007. 
BEAVER, D.; ROSEN, R. Studies in scientific collaboration part I: the professional origins of scientific co-authorship. Scientometrics, Dordrecht, v. 1, n. 1, p. 65-84, Sept. 1978.

BECKER, P. T. Mentorship in Scientific Writing. Research in Nursing \& Health, Medford, v. 35, n. 3, p. 215-216, June 2012.

BLACKBURN, S. Dicionário Oxford de filosofia. Rio de Janeiro: Jorge Zahar Editor, 1997.

CAVALHEIRO, J. S. A concepção de autor em Bakhtin, Barthes e Foucault. Signum: Estudos de Linguagem, Londrina, v. 11, n. 2, p. 67-81, dez. 2008.

CORTINA, A.; MARTINEZ, E. Ética. São Paulo: Loyola, 2005.

FERNANDEZ MOLINA, J. C.; GUIMARÃES, J. A. C. Ethical aspects of knowledge organization and representation in the digital enviroment: their articulation in professional codes of ethics. In: López-Huertas, M. M. (Ed.). Challenges in knowledge representation and organization for the twenty first century: integration of knowledge across boundaries.

Würzburg: ERGON-Verlag, 2002. p. 487-492.

GLÄNZEL, W. Bibliometrics as a research field: a course on theory and application of bibliometric indicators. [S.1.]: Course handouts, 2003.

HENRY, S. On the Ethics of Collaborative Authorship: The Challenge of Authorship Order and the Risk of Textploitation. Western Criminology Review, Bethesda, v. 14, p. 84-87, 2013.

HILÁRIO, C. M.; GRÁCIO, M. C. C. Scientific collaboration in Brazilian researches: a comparative study in the information science, mathematics and dentistry fields. Scientometrics, Dordrecht, v. 113, n. 2, p. 929-950, Nov. 2017. DOI: $10.1007 / \mathrm{s} 11192-017-2498-4$.

HJØRLAND, B. Domain analysis in information science: eleven approachestraditional as well as innovative. Journal of Documentation, Bingley, v. 58. n. 4, p. 422-462, 2002.

KATZ, J. S.; MARTIN, B. What is research collaboration? Research Policy, North Carolina, v. 26, n. 1, p. 1-18, Mar. 1997.

KONDER, L. O futuro da filosofia da práxis. Rio de Janeiro: Paz e Terra, 1992.

KROKOSCZ, M. Autoria na redação científica. Informação \& Informação, Londrina, v. 20, n. 1, p. 319-333, jan./abr. 2015. 
LEMOS, A. A. B. de. Publicar e perecer. Ciência da Informação, Brasília, v. 34, n. 2, p. 7-8, maio/ago. 2005.

LIMA, A. P. L. de. et al. Conceitos, práticas e desafios da responsabilidade social na produção científica. Perspectivas em gestão do conhecimento, João Pessoa, v. 2, n. 2, p. 30-42, 2012.

MANDAL, J.; PARIJA, S. C. Ethics of authorship in scientific publications. Tropical parasitology, Mumbai, v. 3, n. 2, p. 104-105, July/Dec. 2013.

MARCONDES, D. Iniciação à Filosofia. Rio de Janeiro: Jorge Zahar, 2001.

MARTINS, M. H. P. A ética em questão. Palavra chave, São Paulo, n. 8, p. 34, out. 1994.

MONTEIRO, R. et al. Critérios de autoria em trabalhos científicos: um assunto polêmico e delicado. Brazilian Journal of Cardiovascular Surgery, São Paulo, v. 19, n. 4, p. III-VIII, 2004.

MONTENEGRO, M. R.; Alves, V. A. F. Critérios de autoria e co-autoria em trabalhos científicos. Acta Botânica Brasílica, Feira de Santana, v. 11, n. 2, p. 273-276, dez. 1997.

MUCCIOLI, C. et al. A ética, a pesquisa e a publicação científica. Arquivos Brasileiros de Oftalmologia, São Paulo, v. 69, n. 6, p. 787, nov./dez. 2006.

NATIONAL INSTITUTES OF HEALTH. Guidelines and Policies for the Conduct of Research in the Intramural Research Programs at the NIH. 5. ed. 2016.

NEWMAN, A.; JONES, R. Authorship of research papers: ethical and professional issues for short term researchers. Journal of medical ethics, London, v. 32, n. 7, p. 420-423, July 2006.

PESSANHA, C. Critérios editoriais de avaliação científica: notas para discussão. Ciência da Informação, Brasília, v. 27, n. 2, p. 226-229, maio/ago. 1998.

PETROIANU, A. Autoria de um trabalho científico. Revista da Associação Médica Brasileira, São Paulo, v. 8, n. 1, p. 60-65, 2005.

PRADO, G. M. Da ordem presente à razão futura: alguns pontos de vista sobre o tema Ética na produção científica do IBCT (1972-1996). Ciência da Informação, Brasília, v. 25, n. 3, p. 319- 329, set./dez. 1996.

SÁ, A. L. Ética profissional. São Paulo: Atlas, 2000. 
SÁNCHEZ VÁZQUEZ, A. Ética. Rio de Janeiro: Civilização Brasileira, 1975.

SEVERINO, A. Filosofia. São Paulo: Cortês, 1994. 196 p.

SILVA, E. G.; HILÁRIO, C. M.; MARTINEZ-ÁVILA, D. Análise da autoria em diretrizes de autores de periódicos brasileiros. In: ENCONTRO NACIONAL DE PESQUISA DA ASSOCIAÇÃO NACIONAL DE PESQUISA E PÓSGRADUAÇÃO EM CIÊNCIA DA INFORMAÇÃO, 18., 2017, Marília. Anais... Marília: UNESP, 2017. Doc. não paginado.

SMITH, M. The trend toward multiple authorship in psychology. American Psychologist, Washington, v. 13, p. 596-599, 1958.

SROUR, R. Poder, cultura e ética nas organizações. Rio de Janeiro: Campus, 1998. p. 270-271.

STRANGE, K. Authorship: why not just toss a coin? The American Journal of Physiology-Cell Physiology, Bethesda, v. 295, n. 3, p. C567-C575, Sept. 2008.

SUBRAMANYAM, K. Bibliometric studies of research collaboration: a review. Journal of Information Science, Aberystwyth, v. 6, n. 1, p. 33-38, Jan. 1983.

VALLS, A. L. M. O que é ética. São Paulo: Editora Brasiliense, 1994.

VANZ, S. A.; STUMPF, I. R. C. Colaboração científica: revisão teóricoconceitual. Perspectivas em Ciência da Informação, v. 15, n. 2, p. 42-55, maio/ago. 2010.

VASQUEZ, A. S. (Ed.). Ética. Rio de Janeiro: Civilização Brasileira, 1995.

WECKERT, J.; ADENEY, D. Ética informática y las ciencias de la información. Madrid: Fragua, 2000.

WITTER, G. P. Ética e autoria na produção textual científica. Informação \& informação, Londrina, v. 15, n. especial, p. 131-144, 2010.

\title{
Ethical aspects of coauthorship in scientific publications
}

\begin{abstract}
Scientific co-authorship presupposes the active intellectual participation of all authors in the elaboration of a research. However, there are many understandings about the concepts of scientific collaboration and coauthorship activities, which sometimes confuse researchers during the authorship attribution process in collaborative research. This essay aims to reflect on the ethical aspects of the attribution of authorship in scientific
\end{abstract}


publications, from the reflection and debate about participation and collaboration in the development of scientific research and, subsequently, responsibility on the results generated and communicated to the scientific community. Specifically, it aims to analyze the concepts and functions of an author, to highlight the distinction between the activities of scientific collaboration and co-authorship and to deal with the ethical aspects in the attribution of authorship in science. Although there are norms of ethical conduct in science we consider that researchers should reflect about the problems of attribution of authorship, since the ethical aspects of scientific practice are inseparable from socials, and political questions and praxis of a scientific field. It concludes that dealing with the ethical aspects of co-authorship during the formation of the researcher can be a strategy to minimize problems associated with this issue and encouraging studies of this nature tends to provide discussions about the subject, making it part of the Knowledge construction process.

Keywords: Ethics in coauthorship. Ethics in collaboration. Ethics in scientific publications. Coauthorship. Scientific Collaboration.

Recebido: 05/09/2017

Aceito: $13 / 11 / 2017$ 